\title{
Violências sexuais: incesto, estupro e negligência familiar
}

\author{
Sexual violence: incest, rape and family negligence
}

\author{
Maria do Carmo Cintra de ALMEIDA PRADO \\ Ana Carolina Covas PEREIRA'
}

\begin{abstract}
Resumo
Este artigo discute os desafios envolvidos na assistência em Terapia Familiar Psicanalítica de uma mulher de 41 anos, vítima de incesto dos sete aos 12 anos, seguido de duas situações de estupro, que implicaram em um aborto e no nascimento de uma menina, com sete anos na ocasião do estudo. Apresentou-se infantilizada, dependente, sem autonomia, com diagnóstico de borderline. Em nenhum momento, encontrou na mãe alguma forma de apoio. Pais, em conluio perverso e abusivo, causam danos lesivos à constituição psíquica de seus filhos, cujas vidas ficam destroçadas, e levam a pensar que eles próprios tenham tido seus psiquismos danificados, marcados por vivências impensáveis, revertidas em segredos. Transformar e reparar são os objetivos de toda Terapia Familiar Psicanalítica e, nestes casos, os desafios são imensos, pois, entre as várias conseqüências clínicas de tal situação, há um ódio exacerbado à realidade, intensas vivências persecutórias e a reedição transferencial da dinâmica familiar no enquadre terapêutico.
\end{abstract}

Unitermos: Agressões sexuais. Estupro. Incesto. Relações familiares.

\begin{abstract}
This paper examines the challenges involved with the Psychoanalytical Family Therapy (PFT) care of a 41 year-old woman, a victim of incest between the age of 7 and 12, followed by two incidences of rape that resulted in one abortion and the birth of a girl, who is currently 7 years of age. The patient presented childlike behavior, no measure of independence and a borderline diagnosis. She could never rely upon her mother for any kind of support. Parents, in perverse and abusive collusion, cause considerable damage to their children's minds, their lives becoming devastated, leading us to believe it is they who have had their psyches damaged, tainted by unthinkable experiences transposed into secrets. To transform and repair is the aim of every Psychoanalytical Family Therapy and, in these cases, there are enormous challenges for the psychotherapist as the family has an acute aversion to reality, it displays intense feelings of persecution and the family psychodynamic spills overinto the therapy sessions.
\end{abstract}

Uniterms: Sex offenses. Rape. Incest. Family relation.

\section{Introdução}

Os contos de fada vêm sendo recontados ao longo dos tempos e propagados em diferentes versões. Ao lidar com questões humanas universais, eles apresentam problemas e soluções e transmitem, ao mesmo tempo, significados manifestos e latentes, comunicando-se com todos os níveis da personalidade humana, seja ela infantil ou adulta. Bettelheim (1978) considera que, à medida que as estórias se desenrolam,

$\cot$

- Universidade do Estado do Rio de Janeiro, Hospital Universitário Pedro Ernesto, Setor de Terapia de Família. Brigadeiro 28 de Setembro, 77, Vila Isabel, 20551-030, Rio de Janeiro, RJ, Brasil. Correspondência para/Correspondence to: M.C.C.A. ALMEIDA PRADO. E-mail:<cintradealmeidaprado@yahoo.com.br>. 
elas validam e dão forma a pressões do id, apresentando vias para sua satisfação de acordo com as demandas do ego e do superego.

Pele de Asno, um conto conhecido de Perrault (1883/1978), aborda a questão dos desejos incestuosos por meio da intenção de um rei de se casar com sua filha. Viúvo, estava preso à promessa que fizera à sua mulher, a rainha, em seu leito de morte, de só vir a se casar novamente se fosse com uma mulher mais bonita e mais virtuosa do que ela. Após buscas infrutíferas, ele começou a notar que a beleza, os encantos e a inteligência da princesa, sua filha, ultrapassavam muito os da rainha morta. Tomado por violento amor, declarou-Ihe sua decisão de desposá-la, já que somente ela poderia livrá-lo de seu juramento. A princesa, cheia de virtude e pudor, sentiu-se desfalecer diante de tão terrível proposta. $O$ rei procurou aconselhar-se com um velho druida que, por interesses pessoais ambiciosos, atenuou a gravidade do crime que ele pretendia cometer - afinal, perguntando-se a qualquer menininha com quem ela desejará se casar quando crescer, a resposta será sempre a mesma: "com papai!".

Da perspectiva da criança, o conto aborda toda uma série de fantasias e desejos da menina pequena enredada com sua trama edípica: superar a mãe em tudo e vir a substituí-la, casando-se com o pai. Apresenta tais desejos como proibidos, como um crime grave. Se o desejo do pai pela filha pode ser interpretado como decorrente das identificações projetivas dela a seu respeito, o desejo dele também é abordado pelo conto, com o rei se apresentando confundido na linguagem de sua paixão, como diria Ferenczi (1933/1992). O desejo deste pai teve que ser interditado pela fada madrinha, para quem a função paterna estava bem estabelecida, permitindo-Ihe, assim, auxiliar na resolução do conflito. Contudo, além dos contos de fada, a realidade pode ser bem diferente.

O conto A bela adormecida tem uma versão do século XVI, portanto, anterior a Perrault e conhecida por ele. Intitula-se Sol, Lua e Tália, e aborda uma situação de estupro. Seu autor é um napolitano chamado Giambattista Basile (Canton, 1994). Nessa versão, o pai de Tália, recém-nascida, é prevenido pelos sábios de que ela morreria de um ferimento no dedo. Embora o pai tivesse proibido a permanência, no reino, de qual278 quer objeto semelhante à roca, ela encontra uma e se fere. Tália entra em um estado de sono ininterrupto, similar à própria morte, e é abandonada no castelo por seu pai. Em meio a uma caçada, outro rei chega ao castelo e, impactado pela beleza do corpo inerte de Tália, violenta-a, abandona-a e esquece o fato. Nove meses depois, ela dá à luz um menino e uma menina, que são chamados de Sol e Lua. Apesar de continuar desacordada, as crianças mamam em seu peito e, certo dia, por engano, o menino suga seu dedo, remove o fuso que se encontrava cravado e devolve-lhe, assim, a vida. A seguir, o mesmo rei volta por acaso ao castelo e descobre o que acontecera, vendo-se com uma família ilegítima, porque ele já era casado antes do incidente. A rainha adivinha o que se passara e, furiosa, planeja matar os filhos ilegítimos do marido. Por um artifício, consegue a posse deles e entrega-os ao cozinheiro, com a ordem de prepará-los para a refeição do marido. Apiedado, ele poupa as crianças e as substitui por outro tipo de carne. Depois, a rainha também tenta matar Tália e, quando está prestes a consegui-lo, o rei chega e salva seu verdadeiro amor.

Canton (1994) comenta que todas as versões clássicas do conto A Bela Adormecida, ou seja, as mais conhecidas, invertem o ato de violação, transformando-o em salvação, de forma a torná-lo uma lição de moral e de comportamento sexual, paciência e docilidade para a mulher.

Muitas interpretações podem ser feitas a partir da versão de Basile, considerando todas as relações conflituosas de que trata. Para os objetivos deste trabalho, optou-se apenas por mencionar o ato sexual imposto, sem o consentimento da mulher, com a gravidez decorrente, e expor os versos com os quais termina esta versão, que pode ser considerada a original: "Gente feliz, é o que se diz, É abençoada pela Sorte na cama".

Por meio dos contos de fadas, as crianças, de um modo geral, têm acesso à elaboração e à simbolização de questões universais que envolvem sexo, desejo, lei e morte. Mas aquelas que estão expostas a situações reais de incesto e abuso sexual, muitas vezes em suas próprias casas, vêem-se profundamente sós, sem possibilidade de simbolizar e transformar essas experiências tão nefastas, cujas marcas serão carregadas pelo resto de suas vidas. Isto se agrava, em muitos casos, por não poderem contar, em seu meio familiar, com suporte e tratamento apropriados, o que lhes acontece, devido ao próprio comprometimento parental. 
Neste trabalho, apresentam-se primeiramente as conseqüências das situações de abuso sexual na infância, que não são esquecidas pelo sujeito com o passar do tempo. A seguir, abordam-se questões pertinentes à relação entre a vítima de incesto e sua família, tecendo-se algumas considerações sobre o universo do estupro e sobre a negligência familiar, para apresentar-se, finalmente, um caso clínico, atendido em serviço de psiquiatria de hospital universitário público.

\section{Quando, com o tempo, não passa: as marcas deixadas pelo abuso sexual na infância}

Existem elementos que são determinantes no impacto psicológico da vivência de abuso sexual na infância e suas conseqüências. Alguns implicam em um melhor prognóstico, outros não. De acordo com Gauthier (1994), aqueles que favorecem um melhor prognóstico dizem respeito a: 1) Família unida no momento do abuso; 2) Ter se dado o abuso uma única vez; 3) Abuso se integrando em uma relação afetiva sem violência; 4) A criança tendo certa maturidade e conhecimento sexual, 5) Tratar-se de abuso extra-familiar; 6) Meio familiar com capacidade de escuta, permitindo a revelação; 7) A revelação ser um segredo mediatário absoluto; 8) Busca rápida de assistência; 9) Existência de equipe especializada e de local apropriado para atendimento; 10) Escuta, exames e assistência reagrupados desde a revelação, em tempo hábil; 11) Suporte do meio familiar; 12) Em um primeiro tempo, manutenção do enquadre de vida na ausência do agressor designado; 13) Encaminhamento assistido, com apoio judicial; 14) Conhecimento do futuro do acusado, se ele é julgado culpado e se não é da família.

Já aqueles que envolvem um pior prognóstico implicam em: 1) Problemas familiares precedendo ao abuso; 2) Abusos repetitivos por um período longo; 3) Abuso cometido por meio da força ou de ameaças de violência; 4) Criança com baixa idade; 5) Abuso intra-familiar cometido pelo pai natural; 6) Intensidade das ameaças vividas pela criança; 7) Meio isolado, pouco rico em relações, não permitindo a revelação; 8) Falta de discrição, exposição ao meio, inclusive à mídia; 9) Revelação não tratada ou não levada em consideração (quando a vítima é desmentida); 10) Multiplicidade de interventores e falta de coordenação da assistência; 11)
Muita demora para se tomar decisões que impeçam o abuso, acarretando desconsideração e esquecimento da saúde psíquica da vítima; 12) Multiplicação de exames físicos da vítima; 13) Criança desconsiderada e não ajudada em sua família; 14) Retirada da escola e da sua própria situação de vida; 15) Retorno do abusador designado ao domicílio da criança, no momento da revelação; 16) Convivência com o abusador forçada pela mãe; 17) Comparecimento da criança como autora da queixa ou como testemunha em tribunal penal.

As conseqüências das situações de abuso sexual na infância implicam em fatores traumáticos, internos e externos, em curto, médio e longo prazos, e dependem de uma série de aspectos, tais como a idade da vítima, a recorrência das situações abusivas, a complacência e a conivência familiares, as reações familiares após a revelação, agravadas quando implicam em desmentir a criança, denegação e permanência da situação abusiva, com o silêncio e o conluio familiares, sem contar uma possível falta de compromisso por parte de outros adultos do ambiente da criança, inclusive do sistema escolar e de saúde. Membros da família extensa podem conhecer a situação e preferir se calar para "não separar a família".

No que diz respeito aos fatores traumáticos internos, existe uma diferença significativa quando a criança encontra na mãe uma figura protetora e quando não encontra: no primeiro caso, medidas são tomadas para sua assistência e proteção; no segundo, ela é desmentida e permanece exposta às situações abusivas. A violência à qual ela é submetida tem, então, duas faces: a do abuso sexual em si e a do abuso moral, pela denegação materna. Isto aumenta a confusão da criança quanto às percepções, às emoções e ao entendimento no que diz respeito a si própria e ao meio circundante, sobretudo por sua incapacidade de gerenciar, na idade em que se encontra, e sozinha, suas vivências, que ultrapassam sua capacidade de elaboração e permanecem como fonte de angústia. A vivência traumática sobrevém em um período de construção psíquica e de grande vulnerabilidade. A imagem que a criança tem de si mesma fica distorcida, assim como sua visão de mundo e a compreensão de suas capacidades afetivas, ainda mais por ela estar em uma família cuja comunicação se apresenta particularmente comprometida, calcada na dupla mensagem e no duplo vínculo. 
O desenvolvimento da sexualidade infantil vê-se paralisado ou bruscamente interrompido por causa da confrontação precoce da criança com a sexualidade do adulto, diferente e impressionante, o que interfere com sua vida de fantasia e se impõe à vida da criança sem que ela tenha escolha.

A criança se vê traída quanto à confiança que podia ter nos adultos cuidadores, e invadida por uma série de sensações de mal-estar físico, como estar suja, deformada, ser desprezível, não ter valor, não ser mais como as outras. A auto-estima fica rebaixada e é comum a criança se apresentar irritadiça, agressiva e propensa a atuações, tais como fugas, comportamentos autoquíricos e violência com outras crianças, inclusive com a possibilidade de submetê-las a situações semelhantes às que se viu submetida. São comuns as vivências depressivas, o bloqueio ou queda no rendimento escolar, a evitação de contato, os comportamentos regressivos, distúrbios da alimentação e do sono, pesadelos, episódios de enurese, crises de choro e as somatizações (dores abdominais, de cabeça, tremores, paralisações). Pode ocorrer, ainda, o uso de drogas.

A exposição precoce a situações sexuais, quando em um estado de despreparo, pode levar a criança a atitudes exageradamente sedutoras, masturbação compulsiva, brincadeiras repetidas de conotação sexual e comportamentos francamente desadaptados, como a utilização da sexualidade para fins manipulativos ou de ganhos (prostituição).

Os fatores traumáticos externos estão ligados às repercussões familiares e sociais da situação de abuso. Envolvem a solidão imposta à criança pelo lugar que ela ocupa na família, o silêncio imposto pelas ameaças mais ou menos veladas que Ihe são feitas ou por sua desmoralização devido ao desmentido, as intervenções sociais que expõem a sua intimidade e que nem sempre se mostram as mais apropriadas, a convivência forçada com o abusador ou o possível deslocamento da vida familiar.

Figura-se uma situação de extremo desamparo e impotência, cujas conseqüências, após um longo prazo, mostram-se aparentemente independentes das tentativas de tratamento empreendidas, e estão estreitamente ligadas a um certo número de fatores prognós-

280 ticos (Gauthier, 1994).
Souza (2003) comenta que, em seu trabalho com famílias em clínica privada, depara-se com pessoas que foram vítimas de abuso sexual há até 50 anos atrás, cujas questões permanecem vivas em suas mentes, mantidas como segredos que se apresentam como obstáculos intransponíveis pela dificuldade em nomear os fatos, o que favorece a perpetuação das seqüelas do abuso.

Uma pessoa traumatizada por ter sido vítima de abuso sexual na infância terá que se confrontar, em certos momentos de sua vida - e devido ao próprio ciclo vital - com situações que poderão se apresentar como particularmente estressantes. Estas dizem respeito à iniciação e às experiências sexuais, à constituição da própria família, particularmente com o nascimento de filhos, ou de um em particular, devido à reedição da configuração edípica (Faimberg, 2001). Invertem-se, então, os papéis, com a passagem do lugar de filho/ filha para o de pai/mãe, o que favorece que conflitos sejam atualizados. $\bigcirc$ trabalho também pode se tornar fonte de revivências angustiosas, devido à hierarquia laboral, que reedita situações de dependência, de submissão (à chefia, por exemplo), de convivência com pares, com possíveis favorecimentos e/ou ameaças.

Os mecanismos de defesa e de reconstrução da personalidade das antigas vítimas podem se apresentar insuficientes, de forma circunstancial ou crônica, de modo que podem acontecer todas as manifestações de ordem psiquiátrica. Além disso, ocorrem mais freqüentemente diversos outros distúrbios, conforme assinalam Bentovin (1992), Gauthier (1994) e Lethem (1993) ea experiência das próprias pesquisadoras:

1) Vivências depressivas intensas (Na França, Gauthier (1994) situa a síndrome depressiva encabeçando os motivos para a busca de tratamento por pacientes que tenham sido abusados em sua infância; pela ordem, seguem-se os traumatismos sexuais, os transtornos alimentares, sexuais e as chamadas "crises");

2) Risco de suicídio mais elevado do que na população em geral;

3) Ansiedade patológica, envolvendo angústias, fobias etc:;

4) Sentimentos intensos de ódio, culpa e nojo;

5) Distúrbios alimentares nas mulheres (obesidade, anorexia, bulimia), implicando em uma regressão 
à oralidade, uma vez que a genitalidade se apresenta como fonte de intensas angústias;

6) Reações ou comportamentos violentos e de dominação nos homens, em uma tentativa de inverter a situação angustiosa de vítima passiva a executor ativo;

7) Prejuízo à maturidade sexual, que resulta em um desenvolvimento desarmonioso da sexualidade e em dificuldades para poder usufruí-la plenamente;

8) Diminuição do próprio valor sexual, com possibilidade de fobias, dispareunias, bloqueio sexual, promiscuidade, prostituição e homossexualismo. Rouyer (1997) considera que, para a mulher, a orientação homossexual parece ser a busca reparadora de uma ligação com caráter maternal; nos homens, Finkelhor (Gauthier (1994) constatou ser quatro vezes mais freqüente a homossexualidade naqueles que foram vítimas de abuso sexual na infância);

9) Grande indisponibilidade de envolvimento afetivo-sexual (contraposta à promiscuidade), pela falta de confiança e de segurança no parceiro (se há dificuldade em ligar-se, por outro lado, quando isto se dá, face a um rompimento, a elaboração da perda é muito complexa e demorada);

10) No caso das meninas vítimas de abuso, maior disponibilidade em ser vitimadas novamente na idade adulta, devido à fragilidade de suas defesas face às sevícias sexuais;

11) Tendência a comportamentos anti-sociais, que implicam em atitudes delinqüentes e envolvimento com grupos marginais, como expressão de uma busca paradoxal de segurança, quando as imagens parentais não desempenharam satisfatoriamente seus papéis;

12) Agressividade e comportamento criminais, refletindo uma tentativa de acerto de contas com o passado para se adequar ao presente;

13) Uso de drogas, que, no entender de Gauthier (1994), deve ser considerado como uma tentativa de automedicação, e tem relação direta com o ressurgimento dos afetos ligados ao traumatismo em si. (A escolha da droga não se dá por acaso: há as estimulantes e as anestesiantes. Gauthier assinala que as primeiras permitem uma revivência da experiência e das emoções, como meio de gerir, aceitar ou reconstruir, mas há que se considerar outro aspecto: a excitação que as drogas estimulantes promovem tem a ver com uma tentativa de driblar o mal-estar e intensas vivências depressivas; as segundas favorecem o esquecimento ou a diminuição de um estado de tensão insuportável, ligado aos afetos vivenciados no passado, e entre elas se incluem o álcool e tratamentos com psicotrópicos em pessoas socialmente bem inseridas);

14) Uniões instáveis com companheiros inadequados, violentos e/ou abusivos;

15) Maior suscetibilidade de que filho(s) ou filha(s) seja(m) exposto(s) a situações de abuso sexual, repetindo-se o abuso de forma transgeracional. (Isto parece estar relacionado à configuração edípica, conceito que inclui relações recíprocas de filhos com os pais e de pais com os filhos, necessariamente dissimétricas desde o início da vida da criança, em virtude de seu desamparo. Faimberg (2001) pôde notar que, ao interpretar o funcionamento narcisista de pacientes na transferência, com freqüência estes respondiam associando fragmentos da história de seus pais. A autora considera que o que se transmite não é sempre um conteúdo, mas um modo narcisista de solução de conflitos, isto é, os pais transmitem ao filho um funcionamento narcisista ao qual eles apelaram na tentativa de resolver seus próprios problemas intrapsíquicos, incluindo seus conflitos edípicos).

\section{A vítima de incesto e sua família}

O incesto diz respeito, essencialmente, a uma interdição social e à transgressão de uma lei nunca enunciada.

De acordo com a teoria freudiana, a criança só tomaria conhecimento da interdição do incesto - presente em toda sociedade humana, constituindo-se em lei universal - em torno dos seis anos de idade. Tal visão foi revista por autores da escola kleiniana que entenderam que o complexo de Édipo, conforme proposto por Freud, era o apogeu de um processo iniciado muito antes, tendo suas bases na posição depressiva. Contudo, o que é certo é que a criança só experienciará o sentimento de ter transgredido uma lei se ela possuir a noção de que essa lei existe (Gauthier, 1994). Isto indica que os efeitos psicológicos podem ser muito diferentes, dependendo da idade em que a experiência incestuosa se dê e da forma como o tabu do incesto é vivenciado no meio familiar. 
Ao refletir sobre porque o abuso sexual acontece, Souza (2003) desdobra quatro aspectos: 1) a história familiar; 2) as relações abusador-abusado - o que, a seu ver, constitui toda a dinâmica familiar (esta premissa deve ser repensada, pois, em se tratando de criança, ainda que possa haver casos daquelas que convivam apenas com o abusador, costuma haver um terceiro na relação, seja a mãe ou uma substituta, cujo posicionamento em face ao abuso é fundamental para o futuro dela); 3) o segredo e, por fim, 4) a transmissão psíquica entre gerações. Estes aspectos norteiam a escuta psicoterápica e representam grandes desafios técnicos.

No entanto, nos casos de abuso sexual, e particularmente de incesto, como pode ser difícil conhecer a história familiar, exatamente por conta de seus segredos, a comunicação entre os membros da família se apresenta limitada e, por diversas razões, mantêm-se os vínculos de lealdade. O conflito original (Racamier, 1988) não está resolvido nessas famílias, e os processos de separação e individuação encontram-se dificultados, favorecendo que a diferença entre os seres, entre os sexos e entre as gerações não se estabeleça adequadamente. $\mathrm{O}$ incesto se apresenta, então, como uma defesa extrema e derradeira contra a separação, sendo que a família, por sua própria dinâmica, induz ou estimula inconscientemente as situações incestuosas.

Daligand (1995) considera que o traço deixado constantemente pela prática incestuosa é o vazio da história, pela impossibilidade de memorização (grifo do autor). O caso relatado neste artigo revela divergências em relação à hipótese deste autor, que assinala que, freqüentemente, todo o período da infância, e mesmo da puberdade, não é objeto de nenhum fato memorizável e, em seu entender, as vítimas sabem apenas o que lhes foi contado de sua história, sendo que muitos fatos são omitidos. No que diz respeito ao silêncio por parte dos pais, o caso analisado para este artigo corroborou esta informação. Mas também demonstrou que as vítimas lembram-se muito bem de suas vivências, apenas são extremamente cautelosas em abordá-las, demorando para revelá-las na situação psicoterápica, talvez pelos sucessivos desmentidos aos quais se viram sujeitadas ao longo de suas vidas, ou pela necessidade de confirmar um vínculo de confiança com o terapeuta. Além disso, trata-se de vivências que envolvem muita 282 violência, sensações físicas diversas, sentimentos intensos de vergonha, de humilhação e de menosvalia, além de muito ódio, para os quais as palavras parecem não ser suficientes.

Um dos grandes dramas que sofre a vítima de incesto é quando há lacunas na escuta do terapeuta, que se revelam abandonos denegados, sobretudo quando ele insiste em considerar como fantasia os efeitos dos acontecimentos incestuosos reais, a partir de uma visão teórica dos fatos, que se apresenta tentadora por diminuir seu mal-estar. Isto se deve à dificuldade de aceitar a realidade das violências envolvendo o incesto, que vão além do ato abusivo em si, sobretudo quando a criança não encontra suporte e proteção em seu ambiente. Reproduz-se a denegação do acontecimento em sua natureza criminal e sexual, de responsabilidade dos adultos envolvidos, o que promove repetições na própria situação de atendimento e propicia novas cisões na vítima. Reeditam-se, assim, vivências traumáticas.

Gauthier (1994) considera que a criança que transgrediu a lei do incesto se encontra em uma situação marginal: ela está fora da lei e não tem meios de defesa para se adaptar a esta situação não escolhida por ela, mas imposta pelo adulto de forma mais ou menos insidiosa. A angústia surge, aumentada pelo lado tabu de uma lei, imprecisa e não dita, à qual a criança não pode se referir e diante da qual não pode se posicionar. A ambigüidade das atitudes do pai aumenta a confusão, ainda mais quando ele busca, sem de fato consegui-lo, naturalizar as relações vividas para garantir seus objetivos. A criança não pode mais contar com um pai que seja um modelo de respeito à lei, e a perturbação e a falta de limites reforçam seu sentimento de culpa. Traumatizada, ela não tem mais segurança simbólica nem física.

Ainda de acordo com esse autor, o silêncio por parte da criança se estabelece: a) pelas ameaças que a encerram em um constrangimento poderoso, que leva ao mutismo; b) pela introjeção de sua própria culpa por se sentir responsável pelo que ocorre, o que faz com que ela passe a temer a revelação; c) pela deformação da realidade percebida, já que ainda não é capaz de ter um olhar crítico sobre suas próprias experiências - ela pode, assim, crer em tudo e não acreditar mais em ninguém; d) pela fragilidade de seu ego; e e) pelas promessas de brinquedos ou de prazeres próprios para a sua idade. 
A partir do caso analisado para a elaboração deste artigo, depreende-se que a criança pode revelar os fatos, mas é preciso que o adulto para o qual a revelação é feita creia nela, e tome providências a respeito; caso contrário, ela ficará sem recursos e acabará se submetendo, sem mais nada dizer.

Gauthier (1994) trata dos efeitos do silêncio como favorecedor do isolamento cada vez maior da vítima, agravando-se, assim, o impacto traumático e suas conseqüências, permitindo que as situações de abuso se reproduzam e favorecendo a síndrome da acomodação sexual, que ameaça levar à não credibilidade da revelação e à retração de testemunhos. O silêncio, assim, engendra o silêncio, que pode ser entendido como uma cumplicidade da criança, até mesmo uma implicação sedutora de sua parte. Gauthier entende o silêncio como um círculo vicioso autodestrutivo.

Ayoun (1995) afirma que os atos incestuosos estão ligados, de modo indissociável, a uma crueldade mental e/ou física, bem como a graves carências afetivas. Eles não dependem de uma fantasia, de um mito, de um rito de passagem, nem de um casamento proibido entre adultos. Considera que essas relações sexuais impostas por um adulto, parente biológico ou não, a uma criança que vive sob seus cuidados, se dão em um clima de terror sem palavras. Sua hipótese é que esse "assassinato psíquico" consiste em um atentado ao vínculo de pertença à espécie humana, no foro íntimo e nas relações com o exterior do sujeito vitimado, assim como dos agressores. O incesto promove, então, uma desarticulação de todos os vínculos, sejam eles sociais, familiares ou pessoais.

\section{Algumas considerações sobre o universo do estupro}

O estupro foi muito pouco estudado enquanto manifestação psicopatológica. Seu caráter delitoso e a ausência de elaboração mental por parte do estuprador o situam no campo das anomalias dos comportamentos sociais e da criminologia.

Balier (1995) relata que, desde os anos 80, na casa prisional de Varces, chamou sua atenção a capacidade que certos estupradores tinham de realizar um trabalho psicanalítico. Ao longo dos anos, ele e a equipe de Varces puderam apurar seu enfoque e, apesar de um número relativo de fracassos, constataram que alguma coisa podia ser feita com eles, mas que o tratamento só seria possível dentro da lei, isto é, em referência à lei. As idéias expostas a seguir estão calcadas em sua experiência.

O campo da psiquiatria pura e simplesmente exclui o estupro, salvo quando envolve elementos sádicos, de acordo com o DSM III, o que diz respeito a 10\% dos estupros, em média, com base em alguns estudos. No que concerne a esta categoria de agressor, assim como aos pais incestuosos, muito resta ainda a ser decifrado, sobretudo da perspectiva psicanalítica.

A pré-genitalidade caracteriza o estupro. Com a recusa da angústia de castração, a denegação inerente ao funcionamento perverso recai sobre a dimensão genital da sexualidade. Prevalecem a onipotência de pensamento e o ódio à realidade. Por causa da defusão das pulsões, a busca pelo poder e pelo aniquilamento do outro substitui a busca pelo gozo. A violência ocupa a cena, ainda que se apresente combinada com a sedução e com a excitação.

Devido a seu caráter inesperado e incompreensível, o estupro provoca horror e aversão. Podem ocorrer estupros de mulheres adultas, em série, por ocasião de um período de crise na vida do estuprador, ou espaçados em intervalos irregulares, sem motivo aparente. Às vezes o estupro se dá alguns dias após a saída da prisão, sendo que o estuprador cumpria a pena pelo mesmo motivo. Existem estupradores de crianças, meninos ou meninas, e mesmo de bebês, com penetração. Existe o incesto cometido sob ameaça contra uma filha mais velha, bem como em decorrência da tirania de um pai que considera que todos os membros da família Ihe pertencem totalmente.

Quando cometido por psicopatas, o estupro parece mais compreensível, na medida em que se trata de uma mulher conhecida pelo sujeito que se recusa a ir mais longe em um envolvimento amoroso ou que deseja interromper uma relação em andamento. $\mathrm{O}$ ato poderia ser entendido como decorrente da frustração ou vingança, mas Balier (1995) considera que o uso da violência se deve a um sentimento muito mais profundo de inexistência, de vazio psíquico, que pode levar ao assassinato. Do ponto de vista psicopatológico, estuprar e matar não diferem. Trata-se de se apropriar definitivamente do outro, da mãe faltosa, projetando-a no exterior. O objeto perigoso está, assim, ao mesmo tempo dentro e fora da cabeça, invadindo até a loucura. 
Ao referir-se à vítima do chamado crime sexual, Heimann (1952/1978) afirma que ela não morre em virtude de uma experiência sexual, mas por the ser infligida uma violência superlativamente cruel. A seu ver, a crueldade extrema decorre da defusão pulsional, e a violência atuante no psiquismo do perpetrador não se vê mitigada, de nenhuma forma, pela pulsão de vida, restando a ele, como única defesa, desviar o perigo interno de sofrimento cruel e de morte iminente para uma vítima, que se apresenta como um substituto para ele próprio. Explica-se, assim, a total ausência de empatia pelo sofrimento da vítima. Essa catástrofe pulsional faz com que o perpetrador sinta a força da pulsão de morte lavrando em seu íntimo de modo tão intenso, sem a contrapartida da pulsão de vida, que somente o desvio para o exterior poderia salvá-lo do aniquilamento. Entende-se que tal processo esteja atuante, ainda que em diferentes graus, na mente dos pais incestuosos, dos estupradores e dos abusadores sexuais em geral.

Em se tratando de criança, a submissão da vítima à humilhação e ao desrespeito, e o fato de ela ser tratada como coisa, favorecem a erotização do ódio referida por Stoller (1998), e o estabelecimento de um círculo vicioso de situações abusivas e de silenciosa cumplicidade.

\section{Negligência familiar: o mais comum dos abusos}

Desleixo, descuido, incúria, desatenção, menoscabo, desprezo, preguiça, indolência: estes são os significados da palavra negligência (Ferreira, 1985).

Mais da metade de casos confirmados de maus-tratos à criança envolve negligência: 58,0\%, de acordo com levantamento feito por Chalk, Gibbons e Scarupa (2002), nos Estados Unidos. Ainda de acordo com esse levantamento, 21,3\% dos casos correspondem a abuso físico; $11,3 \%$, a abuso sexual, que é mais freqüentemente veiculado pela mídia; e 36,0\%, a vítimas de outras formas de maus-tratos, como abandono e ameaças de castigos severos.

Buscando averiguar esses dados em termos da realidade brasileira, muito poucas informações foram obtidas. Figueiredo e Bochi (2006), em pesquisa sobre violência sexual patrocinada pelo Centro de Referência, Estudos e Ações sobre Crianças e Adolescentes (CECRIA),

284 relatam que foram contabilizados, de maio de 2003 a fevereiro de 2005, pelo Disque-Denúncia, um serviço do governo federal, 1506 casos de abuso e exploração sexual envolvendo crianças e adolescentes. Ressaltam que esses números estão longe de refletir a dimensão do fenômeno no país, devido ao fato de os crimes sexuais estarem entre os menos notificados, como também ocorre no mundo todo. Assinalam que nem sempre a maior quantidade de denúncias é termômetro da gravidade da situação, uma vez que esses indicadores decorrem de uma maior mobilização em determinados estados.

O estado de São Paulo é o líder em denúncias, sendo responsável por 14,53\% das ligações. Em seguida vêm Rio de Janeiro (11,73\%); Rio Grande do Sul (11,44\%); Bahia (8,39\%) e Minas Gerais (7,88\%). Das denúncias recebidas, 32,44\% correspondem a abuso sexual; 17,11\%, a exploração sexual comercial; e 50,45\%, a maus-tratos (Gomes, 2005).

No período em que se elaborou a pesquisa relatada neste artigo, não se encontrou dados estatísticos a respeito da situação de negligência infantil no Brasil. Este é um trabalho ainda a ser feito.

As informações que se seguem têm como base a pesquisa de Chalk et al. (2002). A negligência pode passar despercebida e, em família, diz respeito ao que os pais não fazem e deveriam fazer. A negligência familiar pode ser física, psicológica e/ou educacional, e diz respeito ao fracasso permanente de um pai/uma mãe, ou ainda de um substituto, de prover as necessidades básicas a um menor de 18 anos, que envolvem alimentação, cuidados corporais, higiene, vestuário, abrigo, cuidados médicos e odontológicos, oportunidades educacionais, proteção e acompanhamento.

As conseqüências físicas da negligência podem ser relativamente pequenas, como manchas roxas e pequenos cortes, ou severas, como ossos quebrados, hemorragia ou mesmo morte. A longo prazo, as conseqüências podem ser muito sérias, como cegueira, retardo mental, deficiências físicas, paralisia, comprometimento neurológico, cardíaco ou hepático, enfim, diversas complicações clínicas que podem favorecer uma saúde frágil para o resto da vida.

Da perspectiva psicológica, uma criança é negligenciada quando the faltam suporte apropriado, proteção, atenção, compreensão e afeição. As conseqüências emocionais imediatas são isolamento, medo 
e falta de confiança, que também podem permanecer pelo resto da vida, acrescidos de baixa auto-estima, depressão, dificuldades de relacionamento, prejuízos mentais e emocionais de diversas ordens, ansiedade, transtornos alimentares e tentativas de suicídio.

Enquanto os maus-tratos físicos podem ou não ser imediatamente visíveis, as situações de negligência podem não ser facilmente perceptíveis, mas suas conseqüências possivelmente duram a vida toda, e até mesmo transpõem gerações, afetando crianças, famílias e a sociedade.

Negligência e as mais variadas formas de abuso infantil freqüentemente ocorrem no próprio meio familiar, porém o impacto que provocam não se restringe aí, uma vez que a sociedade como um todo paga um preço pela criança negligenciada e abusada, implicando em custos diretos e indiretos.

Os custos diretos estão associados com a manutenção de um sistema de assistência à criança, envolvendo investigações sobre suas alegações, bem como custos judiciais, execução de mandatos, sistemas de saúde, e especificamente de saúde mental, que possam corresponder à demanda de assistência e tratamento dessas crianças e suas famílias. Os custos indiretos envolvem conseqüências econômicas a longo termo, dizendo respeito à criança negligenciada e abusada, e incluem atividade criminal juvenil e adulta, doença mental, uso de drogas e violência doméstica. Pode também incluir a perda de produtividade devida ao desemprego ou subemprego - provavelmente decorrente do abandono ou do baixo rendimento escolar - custos de serviços de educação especial e sobrecarga para os serviços de saúde disponíveis. Em 2001, os custos diretos foram estimados nos Estados Unidos, pela Prevent Child Abuse America, em 24 bilhões de dólares, e os indiretos, em 69 bilhões de dólares anuais.

Pode-se afirmar que as conseqüências diretas e indiretas da negligência a longo termo, para uma sociedade como a brasileira, são incomensuráveis, a começar pela negligência dos políticos e do Estado. Em uma sociedade em que há fome e abandono social, falta saneamento básico e os sistemas de saúde, de educação e judiciário se apresentam disfuncionais, corrompidos e superlotados, a implantação de sistemas assistenciais ainda se encontra bastante incipiente, sobretudo ao se considerar o tamanho da demanda e as inúmeras carências. Estas envolvem desde espaços físicos adequados, instalações, contratação de pessoal habilitado, até o investimento em pesquisa e na formação e treinamento profissionais apropriados. Seria necessária a implementação de programas de prevenção primária.

\section{Breves observações acerca da abordagem terapêutica}

A terapia de família efetuada com apenas um de seus membros costuma causar estranheza. No entanto, muitas vezes é a única forma de realizá-la, devido às características da própria dinâmica familiar. No caso clínico relatado a seguir, a família não tinha como desconhecer a grave situação enfrentada pela paciente, aqui denominada Marta Célia, que mobilizava a todos. Os familiares interferiam na assistência multiprofissional proposta e, ao mesmo tempo, se recusavam a participar de qualquer atividade oferecida pelos profissionais do serviço. lam além: prejudicavam o andamento do tratamento de Marta Célia, depreciando os profissionais e desestabilizando seu vínculo com eles. Quando algum familiar comparecia ao serviço - a mãe, a irmã ou a madrinha - costumava haver situações embaraçosas, de falatório alto, reivindicativo e em tom agressivo.

A assistência a Marta Célia compunha-se de acompanhamento psiquiátrico e participação em hospital-dia, havendo as reuniões diárias de final de tarde e semanais com os familiares, com a participação de diferentes profissionais, residentes e especializandos das áreas de Psiquiatria, Enfermagem, Serviço Social e Psicologia.

Em face de tal situação, as assistentes sociais solicitaram a Terapia Familiar Psicanalítica (TFP), que foi proposta inicialmente a toda a família uma vez por semana, com sessões de 1h30min, passando-se posteriormente a duas vezes semanais. A situação de atendimento será detalhada na apresentação do caso clínico.

Famílias com transações paradoxais, que oscilam entre a psicose e a perversão, narcísica ou em suas outras manifestações (as parafilias), podem, de imediato, apresentar uma organização aberrante ou aparentar que as coisas funcionam bem. A economia dessas transações é variável e sua aparência não informa sobre o poder de seus sistemas internos. Racamier (1988) considera que 
uma abordagem terapêutica é verdadeiramente possível quando tais sistemas internos não são dotados de um poder muito grande, nem de uma longevidade muito tenaz, sendo a economia interativa essencial.

Cabe lembrar que a perversão narcísica (Racamier, 1987; 1988) não diz respeito à perversão sexual, como se tem o hábito de compreendê-la na linguagem corrente e, de uma maneira mais definida, na clínica psicanalítica, mas sim de uma espécie de perversão moral que opera nas relações do sujeito com seu meio. Trata-se de um modo particular de se proteger dos conflitos internos à custa do meio, podendo ser parcial e passageira, mas predominante em alguns sujeitos, apresentando-se como um movimento mais ou menos profundo, ou então como um estado, uma maneira de ser ou um caráter. Consiste em evitar o impacto dos sentimentos de luto, angústia, desilusão e separação, tratando de colocar ativamente sobre alguém as dores, as dificuldades e os conflitos vinculados a eles. Racamier (1988) propõe que as tarefas psíquicas que um sujeito repele - e existem duas que todo ser humano tem que realizar, que são fazer face à angústia e ao luto fundamental - correspondem ao trabalho de desilusão, separação e individualização, que cabe à criança desde o início e, por ser inerente à vida, não cessa nunca. Quando este trabalho é insuficientemente realizado, recai sobre os ombros dos outros, comumente no próprio círculo familiar. A perversão narcísica consiste, portanto, em uma organização fechada, com um psicótico e uma família que vive surda, autarquicamente, fugindo das relações exteriores e negando suas contradições íntimas. Trata-se, ao mesmo tempo, de uma forma de relação e de uma forma de pensamento.

A perversão narcísica se distingue, portanto, de outras manifestações perversas, as parafilias, que envolvem fetichismo, travestismo, zoofilia, pedofilia, exibicionismo, escopofilia, masoquismo sexual, sadismo sexual e parafilias atípicas, tais como a coprofilia, frotteurismo, clismafilia, misofilia, necrofilia, escatologia telefônica e urofilia. Também há outra questão: perversão narcísica e parafilias podem ocorrer de modo acoplado. De qualquer forma, as práticas perversas se dão como defesa contra a psicose.

Com a proposta de atendimento, a equipe percebeu que tinha tudo contra: os sistemas internos dessa 286 família se mostravam poderosos e longevos. Mas, ainda assim, a equipe insistiu, acreditando na economia interativa. Com o tratamento, previa que novos objetos entrariam em circulação nesse sistema interno familiar e teriam conseqüências (Meyer, 2002). Além disso, ainda de acordo com Racamier (1988), em TFP são possíveis duas modalidades terapêuticas: abordar a família inteira ou um de seus membros, pois basta a modificação de um deles para haver uma incidência sobre o conjunto da economia interativa da família. Sabe-se que há situações em que é preciso que o conjunto do funcionamento seja modificado para que seus membros possam mudar.

\section{Uma náufraga à deriva em sua história}

Marta Célia está se tratando em hospital universitário público. Ela foi encaminhada para TFP pelo serviço social da unidade docente-assistencial de psiquiatria, onde havia sido internada. As assistentes sociais se viram às voltas com dificuldades particulares no andamento das propostas de tratamento da paciente, desde sua internação psiquiátrica, até sua assistência ambulatorial e sua inserção em hospital-dia. Os familiares, quando compareciam à unidade de psiquiatria, pareciam produzir um efeito maléfico sobre a paciente e seus tratamentos, com uma postura de oposição dissimulada aos profissionais. A paciente se apresentava regredida, agressiva, enredada em segredos familiares que não se esclareciam e com os quais as assistentes sociais não sabiam como lidar, havendo histórias de muitos abusos, inclusive sexuais, desde a infância. A mãe, particularmente, apresentava-se inacessível e distante. Os conflitos familiares se mostravam intensos, mas mantinham-se velados. As assistentes sociais entendiam que, sem a assistência à família, tornar-se-ia impossível dar continuidade aos tratamentos de Marta Célia. Ela contava, então, 41 anos, tinha nível médio (incompleto) de escolaridade e pertencia à classe social menos privilegiada.

A família se compunha originalmente de pai, mãe e quatro filhos, dois meninos e duas meninas - a caçula, temporã, 14 anos mais nova. O pai era alcoólatra e morreu de complicações decorrentes do alcoolismo, quando a paciente contava 28 anos. Um filho foi assassinado em circunstâncias pouco claras e o outro morreu de infarto, aos 38 anos. Na época do atendimento, mora- 
vam na mesma casa, ocupando quartos separados, a mãe, a irmã com seu namorado e a paciente com sua filha, que dormiam na mesma cama.

No primeiro atendimento, compareceram a paciente e sua mãe, e logo se delineou a dinâmica transferencial dessa família, pois a mãe dormiu durante a maior parte do tempo da sessão. Marta Célia falou sobre seu irmão "Beto", que a protegia de seu pai - cochichando que falaria a respeito deste em outra oportunidade, porque sua mãe não poderia saber, caso contrário, passaria mal. A mãe nunca mais se dispôs a comparecer aos atendimentos, mantendo-se incomunicável. A família demonstrava se articular em um registro paradoxal: estava presente, mas ausente (dormindo), indicava um segredo, que não era segredo. Apresentavam-se em jogo poderosos mecanismos de defesa, de maneira a se evitarem as realidades factual e psíquica.

Na segunda sessão, compareceram a paciente e sua irmã Fabiane, que questionava a postura agressiva de Marta Célia. Assim, uma queixa era apresentada, com um apelo: que a terapeuta desse conta dessa agressividade. Nenhuma relação era feita quanto a um possível elo entre a agressividade de Marta Célia e a dinâmica familiar e, assim, ela era vista como sendo responsável pelo que não ia bem em família. Admitiu que, naquele mesmo dia, havia mordido um colega do hospital-dia, o que sabia não ser certo. Em seguida, falou sobre o que sabia fazer: tomar banho, vestir-se sozinha e escrever. Propôs à terapeuta o jogo da palavra, mas querendo que ela a deixasse ganhar, como se não houvesse regras no jogo. Esta parecia ser a realidade na dinâmica da família.

A partir do terceiro encontro, Marta Célia passou a vir sozinha, como parece ter sido sua trajetória em família desde sempre: abandonada. Estar só também se apresentava como a condição para poder falar sobre certas coisas, como os abusos sexuais de seu pai, que ocorreram dos sete aos 12 anos. Depois de sua menarca, aos nove anos, o pai manteve com ela apenas relações anais, provavelmente temeroso de uma possível gravidez inconveniente. Aos 12 anos, teria o pai perdido o interesse pela filha que crescia, deixando de ser criança? Não é possível saber. Quem procurava protegê-la, nessas ocasiões, era o irmão Roberto, que não tinha autoridade, no entanto, para interpor-se entre o pai e a irmã e, muitas vezes, acabava apanhando pela tentativa. Era ele quem a auxiliava a limpar-se depois das relações sexuais.

Marta Célia conta que sua mãe sabia de tudo, que houve mesmo uma médica que a atendeu e que, ciente dos fatos, ameaçou a mãe de denunciá-la caso ela não tomasse alguma medida a respeito. A mãe chorou muito, a médica acabou não fazendo nada e tudo continuou na mesma. Foi comentado que a mãe costumava referir-se a Marta Célia como uma"mala sem alça".

Miller (1994) assinala que, na literatura sobre abusos sexuais cometidos contra infantes, a ênfase no estudo da criança reflete o clima predominante, em que o papel do homem continua a não ser contestado, sequer examinado. A mulher na família, a mãe, é freqüentemente vista na literatura como co-responsável pelo abuso, porque é conivente. Como a feminilidade costuma ser associada a cuidados, dedicação e proteção, a mãe não-protetora é considerada patológica. A patologização da mulher revelaria uma história de relacionamento patológico com a mãe, uma história de "maternagem inadequada" ou de incapacidade da mãe em proteger a filha contra abusos sexuais cometidos. No entanto, em sua análise, Miller procura mostrar que "a continuação do poder masculino no contexto do abuso sexual contra crianças depende de as mulheres continuarem a distorcer suas próprias realidades, de tal forma que não existe uma concordância entre elas quanto à natureza de sua experiência" (p.154). Miller entende que há um repúdio à sexualidade feminina quando o objetivo sexual do adulto do sexo masculino é a criança e não a mulher, podendo se dar uma visão de casamento em que a inadaptação do homem seja atribuída à mulher (ou à mãe). Ao desconsiderar esta dinâmica, a mulher sustenta o discurso masculino.

A questão parece ainda mais complexa devido à tendência social, de homens e mulheres, a darem suporte não apenas ao discurso adultocêntrico, mas também ao masculino, tanto pela companheira, dominada, maltratada e/ou "coisificada", quanto por outras pessoas do meio da criança, inclusive possíveis profissionais assistentes, sempre havendo os próprios motivos inconscientes para se deixar influenciar por esses discursos. E, assim, o homem é deixado de fora. A médica que atendeu a Marta Célia, no momento em que não fez nada a partir do choro da mãe, tornou-se conivente 
e passou a sustentar o discurso masculino, desqualificador da palavra da criança, que permanece abusada, não sendo ouvida nem assistida.

A mãe de uma criança submetida pelo pai a assédio violento repete um modelo relacional primitivo conturbado, e mostra-se comprometida com o objetivo de apresentar o pai com a função que lhe é inerente; desta forma, inconscientemente, serve de facilitadora para a transgressão. Ao extrapolar perversamente sua função, o pai expõe sua psicose por meio de sua psicopatia (Carneiro, 2005), mas não apenas ele, já que a mãe, omitindo-se, também o faz por procuração, e sustenta, assim, o discurso masculino perverso. De acordo com Riesenberg-Malcolm (2004), o estado psicótico é uma condição em que os objetos internos estão destruídos e fragmentados, e as principais ansiedades são de desintegração; para encarar tal situação, instala-se a perversão como proteção contra o despedaçamento. Desta forma, a perversão se apresenta como defesa contra a psicose, isto é, as partes psicóticas ficam encapsuladas em uma síndrome perversa, possibilitando ao restante da personalidade o estabelecimento de certo contato com a realidade e a manutenção de um grau mínimo de funcionamento adequado.

Mais do que o remorso inconsciente do pai ou da mãe (Masson, 1984), sua culpa persecutória se expressa em raiva violenta contra a criança, transformada em "coisa", uma "mala sem alça", o que parece ser particularmente evidente nas situações em que a mãe é não-protetora e, portanto, negligente.

Voltando ao caso clínico aqui relatado, as abordagens sexuais do pai à filha se davam sempre na ausência da mãe, após o jantar. Roberto sussurrava à irmã para que comesse bem lentamente, para que o pai desistisse, mas nem sempre isto acontecia, e ele ia procurá-la em seu quarto. Por ocasião do atendimento, a paciente apresentava-se obesa: apesar de comer apenas arroz e peixe às refeições, privilegiava guloseimas. Ingerir doces, biscoitos, pizzas e refrigerantes parecia ser compensatório às angústias mobilizadas às refeições, já que se associavam às situações abusivas que se seguiam ao jantar.

A paciente referiu-se à respiração ofegante do pai às suas costas, lembrança que até o presente a atormentava, e tomava conotações alucinatórias, que pare288 ciam estar relacionadas ao fato de ela ter perfurado o próprio tímpano. Foi uma tentativa infrutífera, pois ela continuava a ouvir a sua voz.

Quando nasceu Fabiane, a irmã temporã, Marta Célia, então com 14 anos, foi a escolhida para ir morar com sua madrinha, escolha em si já sintomática. Seu pai encontrava-se desempregado e sua mãe era a única provedora da casa, mesmo grávida. Carla, a madrinha, a cobria de presentes, roupas, brinquedos e privilegiava suas oportunidades de estudo. Ela e o marido mantinham com Marta Célia uma intimidade que envolvia inclusive verem televisão todos juntos, deitados na mesma cama. Em decorrência de estupro por parte do padrinho, Marta Célia ficou grávida e foi submetida a um aborto. Retornou à sua casa, e Carla separou-se do marido. Ao não denunciá-lo criminalmente, também sustentou o discurso masculino.

A madrinha, culpada, desde então procurava prover Marta Célia em termos materiais, o que acabava sendo motivo de muita briga em família, particularmente com Fabiane, que se opunha.

Várias outras situações foram se sucedendo ao longo do atendimento: a paciente quebrou coisas em casa e recusou-se a dormir na mesma cama com sua filha, fruto de um segundo estupro, por parte de um conhecido que a paciente confusamente via como namorado; apanhava da tia materna, sua acompanhante em determinadas ocasiões, com toalha molhada e com colher de pau, e mostrava seus hematomas à terapeuta. Por outro lado, Fabiane questionava a autonomia de Marta Célia, que desejava aplicar em casa o que aprendia no hospital-dia, como utilizar-se apropriadamente dos talheres e servir a própria bebida. Enquanto a paciente questionava o medo que todos pareciam ter em deixá- la fazer as coisas sozinha, a família parecia se ressentir de não dar os cuidados que podia dar, cuidados muito básicos, como servir a paciente de comida ou bebida, ou cortar a carne em seu prato. O tratamento que the dispensavam era infantilizante e impeditivo ao seu desenvolvimento. A família parecia querer que a paciente permanecesse sob seus cuidados, que eram, na realidade, totalmente inadequados. Conservá-la fechada no círculo familiar se apresentava como uma garantia para que os segredos familiares se mantivessem ocultos.

Em atendimentos posteriores, Marta Célia brincava de esconder para a terapeuta achá-la, fazendo a equipe pensar sobre seu desejo de ser encontrada, vista 
e reconhecida na singularidade de sua pessoa, deslocando-se da posição de objeto "utensilitário" familiar (Racamier, 1987). Também solicitava jogos, sempre pedindo para a terapeuta deixá-la ganhar, porque era assim que acontecia em sua casa: as regras do jogo não valiam.

Certa vez, contou a história de uma "chapeuzinho amarela" que fugia do lobo mau, e nomeou os seus "lobos maus": o pai, o padrinho e um outro, emendando com a estória do patinho feio, que era rejeitado até encontrar o seu grupo. O outro lobo foi o suposto namorado que, um dia, na ausência de todos em casa, estuprou a paciente, então com 34 anos, e fez com que, depois, "sua barriga pesasse muito". Nasceu-lhe uma menina que the era muito estranha, que Ihe causava dor ao ser-lhe colocada ao peito, que lhe era aborrecível porque chorava muito e que a fazia chorar muito também, ao ser acordada para amamentá-la.

Conforme assinalado anteriormente, as meninas vítimas de abuso sexual são mais suscetíveis a serem expostas a novas situações abusivas quando adultas, devido à sua fragilidade estrutural.

\section{Considerações Finais}

Levando-se em consideração os elementos determinantes no impacto psicológico da vivência de abuso sexual na infância e suas conseqüências, as circunstâncias experienciadas por Marta Célia são indicativas de um pior prognóstico. Havia problemas familiares precedendo o abuso, inclusive o alcoolismo do pai. As situações abusivas se iniciaram quando a paciente contava sete anos, e se deram de forma repetitiva, por longo tempo, pela imposição paterna, com a conivência materna. Assim, a convivência com o abusador era forçada pela mãe. $O$ isolamento familiar não permitiu a revelação. Seu irmão Roberto, ciente dos fatos, pouco podia fazer para ajudá-la, por também ser criança e sujeito igualmente à violência do pai, que Ihe batia. Desta forma, a situação não foi tratada nem Ihe foi dada a devida importância. Desconsiderada, Marta Célia nunca foi ajudada em sua família. Quando adulta, devido à fragilidade de suas defesas, viu-se mais vulnerável e novamente exposta a situações de abuso.

Mulheres que foram violentadas na infância por um adulto estimado e investido edipianamente, sobre- tudo quando lhes é imposta a condição de jamais falar sobre o que se passou entre eles, têm toda sua vida simbólica bloqueada, sobretudo em relação à sexualidade. Mais grave ainda será o traumatismo se a violação tiver consistido em coito anal ou na submissão passiva a práticas masturbatórias de um adulto incestuoso (Dolto, 1984).

Apesar de haver sido feito um encaminhamento para terapia de família, Marta Célia ocupou solitariamente o espaço oferecido. Sua irmã compareceu esporadicamente às sessões, basicamente para fazer alguma comunicação ou apresentar alguma queixa relativa à paciente. Costumava mandar seus recados por escrito e evitava comparecer ao atendimento, mesmo quando solicitado. O curioso é que as dificuldades apresentadas pelas assistentes sociais, relativas às propostas de tratamento para Marta Célia e sua inserção institucional e que favoreceram o encaminhamento, deixaram de existir. Os familiares não vinham às sessões, mas as propostas de tratamento tiveram andamento, com a participação ativa da paciente. Reproduziam-se os padrões familiares no enquadre da terapia de família - ausência, abandono, negligência - mas o fato de haver um espaço para falar das relações familiares, passadas e presentes, ainda que tendo quase exclusivamente a paciente como porta-voz, surtiu efeito positivo.

A respeito dos abusadores sexuais de crianças, Carneiro (2005) questiona, enquanto psicanalista clínica: "que chance reparatória restaria ao objeto, se colocado no lugar de um sujeito diante de um analista?" (p.140). Com sinceridade e pesar, diz não pensar que eles consigam ou mesmo desejem estabelecer um processo de análise. No trabalho institucional, onde desembocam casos de abuso sexual contra crianças, constata-se que essa chance reparatória se torna praticamente mínima quando se trata de pai e mãe não-protetores. Foi o caso da mãe da paciente, cuja história revela ter sido negligente com a filha em sua infância, e compareceu a apenas uma sessão da terapia de família, dormindo a maior parte do tempo.

Com relação à vítima, tão negligenciada e acolhida em tratamento somente anos após os abusos ocorridos, o que será possível alcançar, ainda mais considerando-se as dificuldades inerentes às atuais condições dos serviços de saúde públicos? Apesar das dificuldades, 
é preciso pensar que mudanças são possíveis e investir no atendimento. Afinal, ao associar sua situação à história do patinho feio, a paciente do caso relatado assinala ter ainda esperanças de se tornar um cisne.

No enquadre clínico, o passado cruel e violento se revela no decurso da transferência - não apenas da paciente, mas também dos familiares, por meio de sua ausência - abrindo-se vias de simbolização e elaboração, por meio de uma escuta que lhe dá crédito e fornece sentido.

Se os contos de fada não puderam ser de grande valia em sua infância, porque Marta Célia vivia o horror da realização de seus desejos, que não podiam ser apenas fantasiados, bem como estava exposta, indefesa, ao real da crueldade parental, será pela associação com alguns deles - como "o patinho feio" ou "a chapeuzinho amarela", em sua adaptação pessoal do tradicional conto - que expressará vias de simbolização de suas experiências e suas expectativas de superação?

É bonita e delicada a imagem apresentada por Carneiro (2005) a respeito da assistência às vítimas: um objeto valioso que passa por um processo de restauração sempre apresentará marcas; da mesma forma, a criança vítima de abuso sexual, especificamente um crime de estupro incestuoso, carregará suas cicatrizes, sendo um adulto marcado. No entender da autora, o recurso mais completo para atenuar essas marcas é a psicanálise.

Torna-se preocupante a situação de Roseane, nome atribuído pelas pesquisadoras à filha de Marta Célia, atualmente com sete anos. Fruto da violência de pai estuprador e não reconhecida por ele, a menina também o é precariamente por Marta Célia, que apenas "de brincadeirinha" aceita ser chamada de mãe, preferindo, "na realidade", ser chamada pelo nome. Só que a realidade é que ela é a mãe. Ambas dormem na mesma cama, e parecem ser tratadas como duas irmãs pequenas pelos demais membros da família. Uma geração é, assim, abolida, com a avó (re)assumindo o papel de mãe, com seu histórico de abandono e negligência. Marta Célia, ao referir que sua barriga foi ficando pesada após o segundo estupro, não indica que tivesse um conhecimento de que estava grávida, ou se chegava a tê-lo, ele era negado. Sua experiência era a de que um bebê Ihe foi imposto, que Ihe machucava o seio e Ihe fazia
Roseane é uma criança em situação de risco, inclusive de vir a ser vítima de abuso sexual. Já é de notório saber que filhos de mães abusadas sexualmente em sua infância estão mais expostos a também sofrer abuso sexual. Além do mais, se Roseane não tem exatamente um delírio como herança (Enriquez, 1993), convive com uma mãe muito mal organizada psiquicamente e com uma família muito comprometida e negligente. Afinal, ela é testemunha e destinatária dessa história familiar. Se não exatamente o delírio, ela poderá ter a violência como herança.

Em uma sessão, Marta Célia falou sobre a história de Jó, sobre suas provações e repetidos sofrimentos, sobre sua solidão, seu desamparo, sua incompreensão ante os desígnios de Deus, mas também sobre seu contínuo apelo a Deus para que não o esquecesse. Terminou essa sessão declamando partes do Salmo 121 - Cântico das peregrinações:

Que alegria quando me virem dizer:
"Vamos subir à casa do Senhor..."
Eis que nossos pés se estacam
diante de tuas portas, ó Jerusalém!
Jerusalém, cidade tão bem edificada,
que forma um tão belo conjunto!
Para lá sobem as tribos, as tribos do Senhor,
segundo a lei de Israel, para celebraro nome do Senhor.
Lá se acham os tronos de justiça,
os assentos da casa de Davi.
Pedi, vós todos, a paz para Jerusalém,
evivam em segurança os que te amam.
Reine a paz em teus muros,
e a tranqüilidade em teus palácios.
Por amor de meus irmãos e de meus amigos,
pedirei a paz para ti.
Por amor da casa do Senhor, nosso Deus,
pedirei para tia felicidade.

\section{Referências}

Ayoun, P. (1995). Inceste, violence et culture. In M. Gabel, S. Lebovici \& P. Mazet (Orgs.), Le traumatisme de I' incest (pp.33-52). Paris: Presses Universitaires de France.

Balier, C. (1995). Agresseurs sexuels: psychopathologie et stratégies thérapeutiques. In M. Gabel, S. Lebovici \& P. Mazet (Orgs.), Le traumatisme de l' incest (pp.199-210). Paris: Presses Universitaires de France.

Bentovin, A. (1992). Trauma organised systems. Physical and sexual abuse in families. London: Karnac. 
Bettelheim, B. (1978). A psicanálise dos contos de fadas. Rio de Janeiro: Paz e Terra.

Canton, K. (1994). E o príncipe dançou... O conto de fadas, da tradição oral à dança contemporânea. São Paulo: Ática.

Carneiro, M. I. N. E. (2005). Um crime parental: possíveis desdobramentos de abusos sexuais em filhos. Revista Brasileira de Psicanálise, 39 (2), 135-142.

Chalk, R., Gibbons, A., \& Scarupa, H. J. (2002). The multiple dimensions of child abuse and neglect: New insights into an old problem. Washington, DC: Child Trends. Retrieved November 20, 2006, a from www.childtrends.org/files/ ChildAbuseRB.pdf

Daligand, L. (1995). Le trauma de l'inceste. In M. Gabel, S. Lebovici \& P. Mazet. (Orgs.), Le traumatisme de I' incest (pp.21-32). Paris: Presses Universitaires de France.

Dolto, F. (1984). Sexualidade feminina. São Paulo: Martins Fontes.

Enriquez, M. (2001). O delírio como herança. In R. Kaës, H. Faimberg, M. Enriquez \& J. J. Baranes. Transmissão da vida psíquica entre gerações (pp.95-127). São Paulo: Casa do Psicólogo.

Faimberg, H. (2001). Dimensão narcisista da configuração edípica. In H. Faimberg. Gerações. Mal-entendido e verdades históricas (pp.160-179). Porto Alegre: Criação Humana.

Ferenczi, S. (1992). Confusão de línguas entre os adultos e a criança. Obras completas, Psicanálise IV (pp.97-106). São Paulo: Martins Fontes. (Originalmente publicado em 1933).

Ferreira, A. B. H. (1985). Novo dicionário da língua portuguesa. Rio de Janeiro: Nova Fronteira.

Figueiredo, K., \& Bochi, S. B. B. (2006). Violência sexual. Um fenômeno complexo. Brasília: CECRIA. Recuperado em novembro 8, 2006, disponível em www.unicef.org/brazil/ Cap_03.pdf

Gauthier, D. (1994). L'enfant victime d'abus sexuels. Paris: Presses Universitaires de France.

Gomes, P. S. (2005). Campanha educativa vai fortalecer o enfrentamento da violência sexual infanto-juvenil. Brasília: Senado, Sala de Imprensa. Recuperado novembro 20,
2006, disponível em www.senado.gov.br/web/senador/ PatriciaSaboyaGomes

Heimann, P. (1978). Notas sobre a teoria dos instintos de vida e de morte. In J. Riviere (Org.), Os progressos da psicanálise (pp.344-365). Rio de Janeiro: Zahar. (Originalmente publicado em 1952).

Lethem, J. (1993). Lightening the burden of the past in brief solution-focused therapy. In The 5th World Family Therapy Congress. Final programme and abstract book (p.90). Amsterdam.

Masson, J. M. (1984). Atentado àverdade. A supressão da teoria da sedução por Freud. Rio de Janeiro: José Olympio.

Meyer, L. (2002). Família: dinâmica eterapia. Uma abordagem psicanalítica. São Paulo: Casa do psicólogo.

Miller, A. C. (1994). O relacionamento mãe-filha e a distorção da realidade nos abusos sexuais na infância. In R. J. Perelberg \& A. C. Miller (Orgs.), Os sexos e o poder nas famílias (pp.151-162). Rio de Janeiro: Imago.

Perrault, C. (1978). Contes: suivis de contes de Madame $d^{\prime}$ Aulnoy. Paris: Gründ. (Originalmente publicado em 1883).

Racamier, P.-C. (1987). De la perversion narcissique. Gruppo 3. Perversité dans les familles (pp.11-27). Paris: Clancier-Guénaud.

Racamier, P.-C. (1988). Perversion narcissique dans la famille du psychotique. Dialogue, 99, 32-41.

Riesenberg-Malcolm, R. (2004) Suportando estados mentais insuportáveis. Rio de Janeiro: Imago.

Rouyer, M. (1997). As crianças vítimas, conseqüências a curto e médio prazo. In M. Gabel (Org.), Crianças vítimas de abuso sexual (pp.62-71). São Paulo: Summus.

Souza, A. M. N. (2003). A família incestuosa e sua dinâmica. In A. C. Oliveira (Org.), Abuso sexual de crianças e adolescentes (pp.21-29). Rio de Janeiro: Nova Pesquisa.

Stoller, R. (1998). Observando a imaginação erótica. Rio de Janeiro: Imago.

Recebido em: 27/6/2006

Versão final reapresentada em: 7/2/2007

Aprovado em: 20/4/2007 